\title{
Evaluation of the Coulomb Friction Coefficient in DC05 Sheet Metal Forming
}

\author{
Gillo Giuliano* \\ University of Cassino, DICeM, Italy
}

This paper describes the identification of the Coulomb friction coefficient for sheet metal forming using a comparison between numerical and experimental results. Using finite element method, the work examines some aspects of the Erichsen test in order to measure the interfacial friction. Preliminary results on the evaluation of a typical tool-workpiece interface are shown for a stainless steel punch vs. a DC05 sheet metal.

Keywords: Coulomb friction coefficient, sheet metal forming, finite element method, Erichsen test

Highlights

- $\quad$ The proposed method examines the Coulomb friction coefficient for sheet metal forming by using the finite element method and experimental results of the Erichsen test.

- Experiments were conducted with a stainless steel punch and DC05 steel sheet metal.

- $\quad$ Specimens were tested in a non-lubricated condition as well as using Grease LB4.

- $\quad$ The numerical-experimental comparison can be considered to be in good agreement especially if using Grease LB4.

\section{O INTRODUCTION}

During the sheet metal-forming processes, whenever the tools and the workpiece are in contact, tangential frictional forces between the sheet metal and the tools are generated. Since the metal flow, the product's cost and quality, and die wear are affected by friction, its effects must be reduced by means of lubricants [1].

In order to accurately analyse sheet metalforming processes, finite element method analysis (FEM) is mostly used. FEM analysis require this modelling of metal sheet's mechanical properties and friction between the sheet and the tools used for the forming process. Among the various models of friction described in literature [2], Coulomb's friction model is the most suitable in cold forming process and when sheet and tools interact significantly.

In this paper, commercial finite element software MSC.Marc is used; it defines friction forces as follows:

$$
f_{t} \leq-\mu f_{n} t,
$$

where $f_{t}$ is the tangential force, $f_{n}$ the normal pressure, $\mu$ the friction coefficient and $t$ the tangent unit vector [3].

The mechanical properties of the sheet have been obtained by means of a standard test at room temperature [4]. The material's constitutive equation is:

$$
\sigma=K \varepsilon^{n},
$$

where $K$ is the strength coefficient and $n$ is the strainhardening exponent.
In order to calculate the friction coefficient, Erichsen's standard test is applied, which, unlike the ones commonly used [5] to [9], is much simpler; moreover, with this test it is possible to determine the properties of the sheet material, as shown in [10].

In [10] to [13] it was shown that the main test output is represented by $d / d_{0}$ where $d_{0}$ is the distance between the punch axis and the blankholder's internal surface, whereas $d$ is the distance between the fracture line and the blankholder's internal surface (see Fig. 1a).

The original distance criterion introduced in [10] to [13], being independent of the values of the material constants, simplifies determining the value of the friction coefficient.

In [12], the influence of the friction on the results of the Erichsen test was analysed. Two types of aluminium alloys were selected as the experimental materials. It was seen that lubrication does not considerably affect the load-displacement curve, whereas it causes a noticeable increase in the ratio $d / d_{0}$ and a reduction in the thickness evaluated at the apex of the specimen. In general, it can be said that lubrication increases formability under biaxial stretching conditions.

In this paper, Erichsen test experiments were conducted with a stainless steel punch and DC05 steel sheet metal in order to evaluate the friction coefficient. DC05 is non-ageing, low carbon steel, which is especially suited for deep drawing and for particular applications, such as automotive components and body panels, components for building, domestic 
Table 1. Chemical composition and mechanical properties of DC05

\begin{tabular}{|c|c|c|c|c|c|c|c|c|}
\hline \multicolumn{5}{|c|}{ Engineering properties } & \multicolumn{4}{|c|}{ Chemical composition } \\
\hline \multirow{2}{*}{$\begin{array}{c}\text { Re max } \\
{\left[\mathrm{N} / \mathrm{mm}^{2}\right]}\end{array}$} & \multirow{2}{*}{$\begin{array}{c}\mathrm{Rm} \\
{\left[\mathrm{N} / \mathrm{mm}^{2}\right]}\end{array}$} & \multicolumn{2}{|c|}{ All\% min } & \multirow{2}{*}{$\begin{array}{c}\text { Vickers } \\
\text { hardness max }\end{array}$} & \multirow{2}{*}{$\begin{array}{l}\mathrm{C} \% \\
\max \end{array}$} & \multirow{2}{*}{$\begin{array}{l}\mathrm{P} \% \\
\max \end{array}$} & \multirow{2}{*}{$\begin{array}{l}\mathrm{S} \% \\
\max \end{array}$} & \multirow{2}{*}{$\begin{array}{c}\mathrm{Mn} \% \\
\max \end{array}$} \\
\hline & & A80 & A50 & & & & & \\
\hline 180 & $270 \div 330$ & 40 & 42 & 100 & 0.06 & 0.025 & 0.025 & 0.35 \\
\hline
\end{tabular}

appliances, etc. The engineering properties and the chemical composition of the studied steel are given in Table 1. Specimens are tested in non-lubricated condition as well as using Grease LB4.

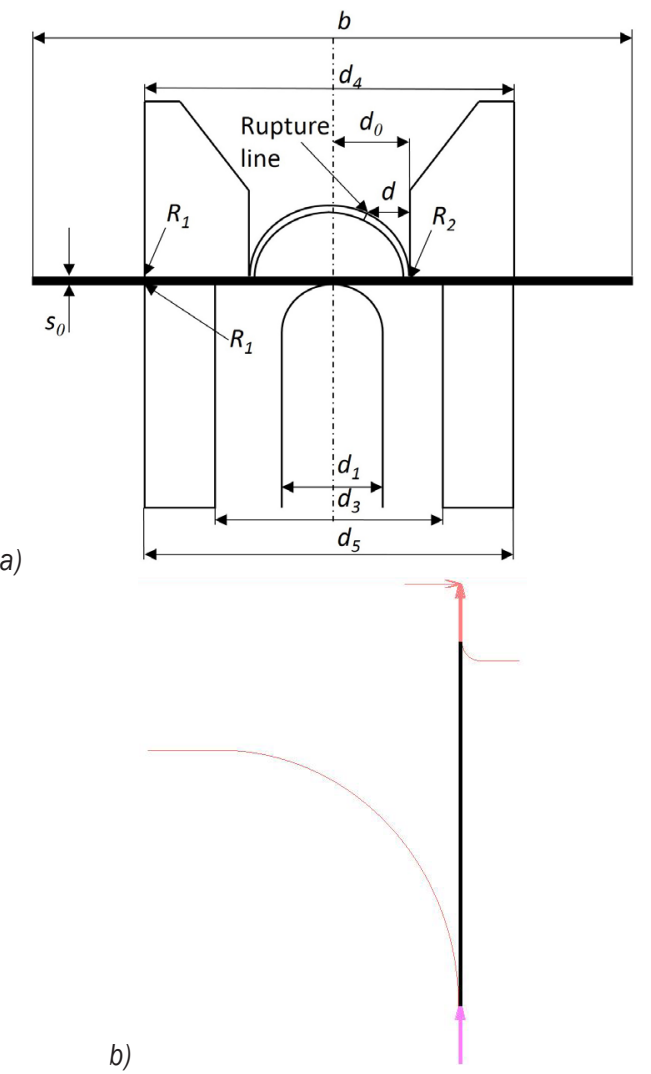

Fig. 1. Erichsen test; a) schematic representation, b) FEM model

\section{FEM MODELLING}

In this paper, two types of tests were simulated using the commercial finite element software MSC.Marc. Fig. 1a shows the schematic diagram of the tools used in the test. The size of the tools, marked with the letter $\mathrm{A}_{0}$ in Table 2, is relative to a standardized Erichsen test [14]. A second series of tests was performed using amplified tools size (indicated by the letter $\mathrm{A}_{1}$ in Table 2) and obtained by multiplying the geometry $\mathrm{A}_{0}$ by a factor of 5 .

Fig. $1 b$ shows the fem schematization of the problem analyzed by geometry $\mathrm{A}_{1}$, but it can also represent geometry $\mathrm{A}_{0}$. Since the model is axisymmetric, only half of the cross-section is represented. With geometry $\mathrm{A}_{1}$, the deformable sheet is discretized in 1312 elements ordered in four rows with 1645 nodes. Geometry $\mathrm{A}_{0}$ uses 384 elements in four rows with 485 nodes. Element type is a fournode, isoparametric, arbitrary quadrilateral written for axisymmetric applications (15). It is hypothesized that the sheet material has a rigid-plastic behaviour according to the model presented in Eq. (2).

Table 2. Symbols and designations

\begin{tabular}{clcc}
\hline \multirow{2}{*}{ Symbol } & \multicolumn{1}{c}{ Designation } & \multicolumn{2}{c}{ Dimension [mm] } \\
\cline { 3 - 4 } & & \multicolumn{2}{c}{ Standard test } \\
\cline { 3 - 4 } & & $\mathrm{A}_{0}$ & $\mathrm{~A}_{1}$ \\
\hline$s_{0}$ & Thickness of the test piece & 0.7 & 0.7 \\
\hline$b$ & Diameter of the test piece & 90 & 450 \\
\hline$d_{0}$ & Inner radius of the blankholder & 13.5 & 67.5 \\
\hline$d_{3}$ & Diameter of the die & 16.5 & 82.5 \\
\hline & $\begin{array}{l}\text { Distance projected on the initial } \\
\text { surface of the sheet and measured } \\
d\end{array}$ & & \\
& $\begin{array}{l}\text { between the rupture line and the } \\
\text { inner surface of the blankholder }\end{array}$ & & \\
\hline$d_{1}$ & $\begin{array}{l}\text { Diameter of the spherical end of the } \\
\text { punch }\end{array}$ & 20 & 100 \\
\hline$d_{4}$ & Outside diameter of the blankholder \\
\hline$d_{5}$ & Outside diameter of the die & 55 & 275 \\
\hline$R_{1}$ & $\begin{array}{l}\text { Outside corner radius of the die and } \\
\text { the blankholder }\end{array}$ & 0.75 & 3.75 \\
\hline$R_{2}$ & Inside corner of the blankholder & 0.75 & 3.75 \\
\hline
\end{tabular}

Fig. 1b highlights two rigid bodies (punch and die are considered to be rigid bodies thus not influenced by mechanical stress in the forming process), the sheet (whose discretization is too thick to be represented) and boundary conditions. Notably on the symmetry axis, the nodes are characterized by a zero displacement in the orthogonal direction to the symmetry axis. The blankholder is not represented, but its effects are replaced by displacement boundaries at nodes placed in the sheet periphery.

The Coulomb friction model is used between the sheet and the tools surfaces.

FEM analysis is used to determine the influence of the $K, n$ and $\mu$ parameters on the Erichsen test results in terms of thickness distribution and locus of 
thinning. $K$ value ranges between $100 \mathrm{MPa}$ and 1000 $\mathrm{MPa}, n$ and $\mu$ vary in the range 0 to 0.5 . The results are highlighted using the strain distribution in the finished component.

\section{EXPERIMENTAL}

The Erichsen test, schematically shown in Fig. 1, is a stretch forming test. It is carried out using a machine specially projected in Cassino University. The punch and the die have been realized in stainless steel.

An Erichsen test on DC05 sheet metal is analyzed. The specimens, of circular shape, were obtained by laser cutting, and are characterized by a diameter equal to $92 \mathrm{~mm}$ and a thickness of about $0.7 \mathrm{~mm}$. Fig. 2 shows an undeformed specimen and a specimen deformed in the non-lubricated condition.

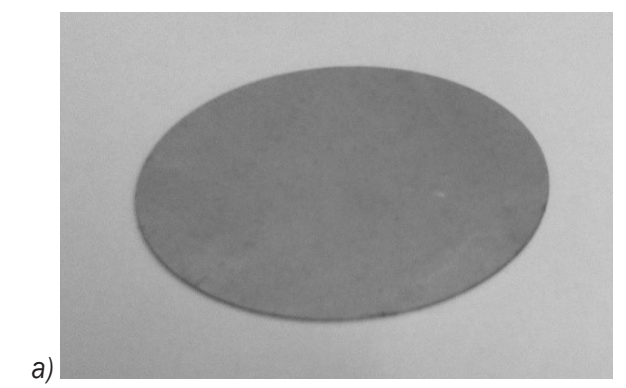

b)

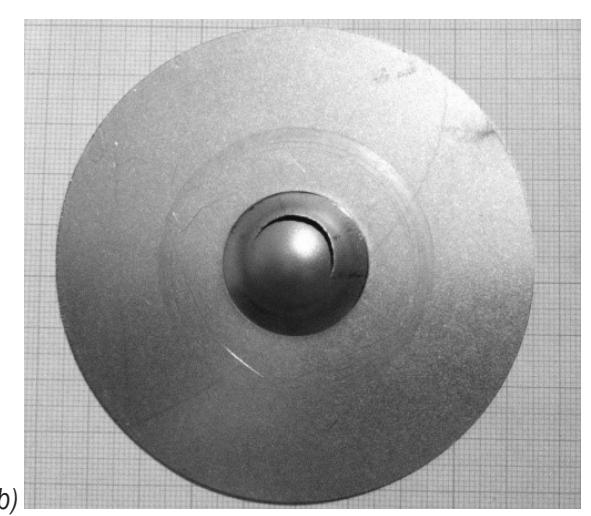

Fig. 2. Photographs of DCO5 specimen used in Erichsen test; a) undeformed specimen, b) deformed specimen

The test consists of the deformation of a circular sheet clamped between the die and the blankholder by a force of $10 \mathrm{kN}$, through a spherical punch. The sheet is deformed until a fracture line is reached. The punch displacement once the break is obtained represents, in millimetres, Erichsen index, which is a measure of the sheet formability.

The testing machine [10] to [12] comprises a workbench on which was set the die containing the circular sheet metal to be tested. The punch was mounted on a vertically-translating machine's crossbeam. The translation movement is produced by two large screws connected to an electric motor through a chain. After a rapid acceleration phase of the beam, the punch pushes the sheet at a constant speed until the break is reached.

At any given moment, by using a laser and a load cell, the pair of load-displacement points is recorded.

To investigate the effect of friction on formability, DC05 specimens are tested both in a non-lubricated condition and using Grease LB4 (lithium grease containing solid lubricant $\mathrm{MoS}_{2}$ ) manufactured with RS 200 motor oil. Black in colour it is used as an alternative to graphite grease for industrial applications.

Tests have been repeated five times and have been carried out at a speed of $0.27 \mathrm{~mm} / \mathrm{s}$. Erichsen index $(E I)$, the thickness measured at the specimen apex, $\mathrm{s}$ and distance between the fracture line and the blankholder's internal surface, $d$, were recorded in every test. $E I$ was measured with a measuring laser, $\mathrm{s}$ with a digital comparator and $d$, represented in Fig. 1a, was obtained via a CAD reconstruction of the specimen, as shown in [12].

\section{RESULTS AND DISCUSSION}

The results of numerical simulations, in terms of thickness and locus of thinning, are independent from the value of $K$ adopted ( $K$ ranges between $100 \mathrm{MPa}$ and $1000 \mathrm{MPa}$ ).

For $n$ equal to 0.5 , Figs. 3, which refer to the results obtained by using the geometry $\mathrm{A}_{1}$ (punch stroke of $50 \mathrm{~mm}$ ) but are also indicative of the tests made at geometry $\mathrm{A}_{0}$, show the values assumed by the principal strains on the top surface of the sheet metal.

In the lubricated condition $(\mu=0)$, the maximum strain (meridional strain) is almost constant in the contact zone between the sheet and the punch while the intermediate strain (circumferential strain) decreases. Therefore, the strain along the thickness (minimum strain) is minimum on the axis of symmetry and increases moving away from the centre. In the non-lubricated condition $(\mu>0)$, the circumferential strain is slightly significant while the meridional strain increases up to the point where it locates the strain then decreases by moving further from the centre.

Fig. 4 relative to geometries $A_{0}$ and $A_{1}$ shows the distance $d$, versus the punch displacement for different values of the friction coefficient $(d$ is the distance between the fracture line and the blankholder's internal surface, see Fig. 1a). In [11], it was found that if the friction coefficient is fixed, the parameter $n$ has 

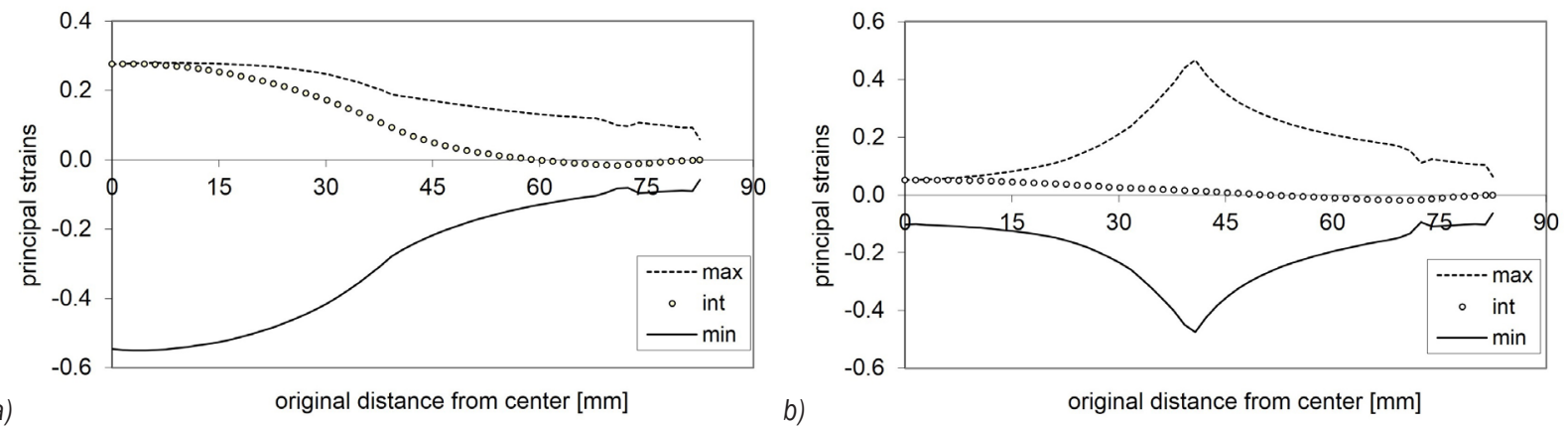

Fig. 3. Geometry $\mathrm{A}_{1}$ : principal strains profile in different conditions of lubrication ( $\left.n=0.5\right)$; a) Iubricated condition $(\mu=0)$; and b) non-Iubricated condition ( $\mu=0.3$ )
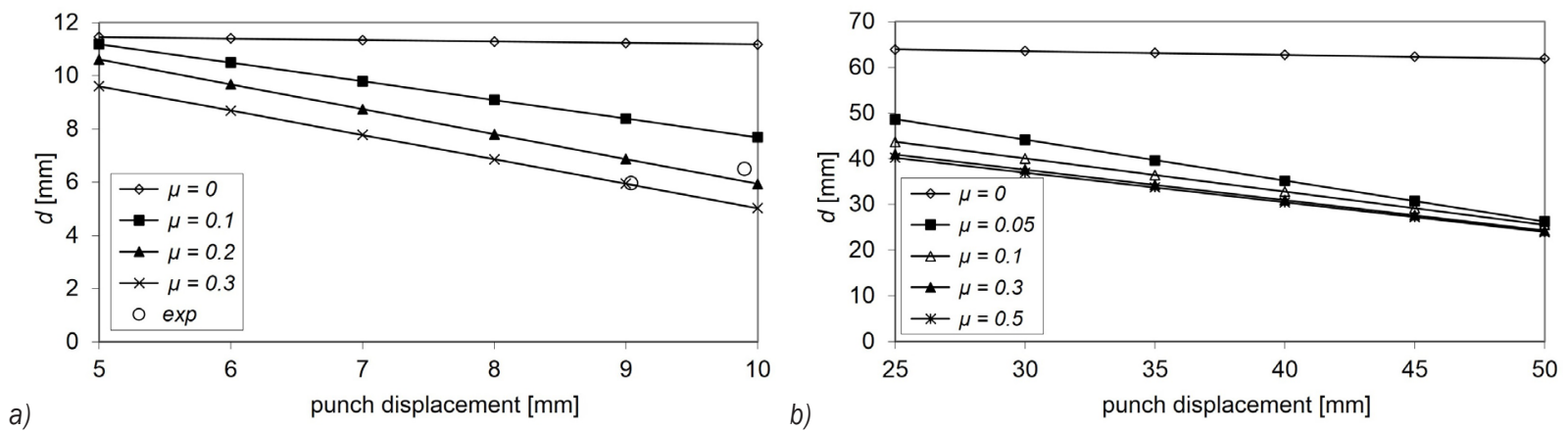

Fig. 4. Relation $d$-punch displacement when varying the friction coefficient; a) $\mathrm{A}_{0}$ geometry and b) $\mathrm{A}_{1}$ geometry

little effect on the results. Therefore, the results shown in Fig. 4 may also be considered independent from the value of strain hardening coefficient [11].

Fig. $4 \mathrm{~b}$ shows that, for the geometry $\mathrm{A}_{1}$, in the lubricated condition $(\mu=0)$ the thinning is localized near the apex of the specimen ( $d$ is constant). In addition, it is noted that, in the non-lubricated condition $(\mu>0)$, the region where the thinning is located moves away from the apex of the sheet $(d$ decreases) increasing the stroke of the punch and is not very dependent on the friction coefficient. In contrast, the figure relative to geometry $\mathrm{A}_{0}$ (Fig. 4a) shows a greater sensibility to the value assumed by the friction coefficient. Therefore, to determine the friction coefficient the configuration $\mathrm{A}_{0}$ will be used.

The friction developing between the punch and the sheet exerts a great influence on test results. To reduce the effects of the friction in experimental activity, a series of tests were conducted by interposing Grease LB4 between the two surfaces in contact.

Table 3 presents the results obtained in the different test conditions. The variables $s, d$ and $E I$ (Erichsen index) are represented in Fig. 1. Table 3 shows that:
- the value of the thickness, $s$, measured at the end of the test at the specimen apex, is strongly influenced by lubrication conditions. Indeed, the presence of the lubricant facilitates the sliding of the punch on the sheet, favouring its thinning. The numerical modelling of this process has made it possible to determine that the meridional strain (maximum strain), in lubrication condition, is distributed in a decreasing trend from the centre to the edge of the specimen (Fig. 3). The absence of lubricant changes the meridional strain distribution, shifting the maximum value far from the apex of the specimen in a position that varies with the value of the friction coefficient between the punch and the sheet itself. The minimum thickness value of the specimen and, therefore, the region of the sheet that will be subject to break after the end of the test are associated to the zone of maximum meridional strain;

- the distance, $d$, tends to increase in the case of lubrication, the rupture line moving to the apex of the specimen;

- the value of the Erichsen index $(E I)$ is high in the lubricated test because the sheet is subjected to uniform strain distribution. 
Table 3. Erichsen test results for non-lubricated condition (absence of lubricant) and for lubricated condition (Grease LB4)

\begin{tabular}{ccc}
\hline & Non-lubricated condition & Lubricated condition \\
\hline$s[\mathrm{~mm}]$ & 0.63 & 0.55 \\
\hline$d[\mathrm{~mm}]$ & 5.95 & 6.49 \\
\hline$E I[\mathrm{~mm}]$ & 9.04 & 9.90 \\
\hline
\end{tabular}

For the evaluation of the friction coefficient we refer to the results reported in Fig. 4a.

Fig. 4a shows the FEM results, based on the distance, $\mathrm{d}$, and obtained with different friction coefficients. The comparison with the results of the real sheet metal process allows determination of the corresponding friction coefficient.

Through the FEM results shown in Fig. 4a, it is possible to determine the relation $\mathrm{d}-\mu$ once the punch displacement is set. Since in Fig. 4a the lines of different friction coefficients are unparalleled, the determined relations differ when varying the punch displacement.

The Coulomb friction coefficient is equal to 0.29 and 0.17 in non-lubricated condition and using Grease LB4, respectively. These values have been used to simulate the Erichsen test. The numerical simulation underestimates the experimental value of the thickness at the apex of the specimen providing a percentage error at the end of the test of $14 \%$ and $9 \%$ in nonlubricated and lubricated conditions, respectively. Conversely, the distance $\mathrm{d}$ is overestimated by $12 \%$ and $2 \%$ respectively.

\section{CONCLUSIONS}

Through geometry $\mathrm{A}_{0}$ (standard Erichsen test), an experimental-numerical process was used to determine the Coulomb friction coefficient in the punch/sheet interface.

In this paper, experiments were conducted with a stainless steel punch and DC05 steel sheet metal using the forming apparatus designed at the Laboratory of Cassino University. Specimens were tested in a nonlubricated condition as well as using Grease LB4.

The Coulomb friction coefficient was 0.29 in non-lubricated conditions and 0.17 when Grease LB4 lubricant was used. Two numerical simulations of the Erichsen test were conducted through such values of friction coefficient. Comparing the experimental results with those of the numerical simulation, the latter, in terms of thickness measured at the specimen apex, are underestimated (with an error of $14 \%$ and $9 \%$ respectively in non-lubricated and lubricated conditions) while in terms of distance, $d$, they are overestimated (with an error of $12 \%$ and 2 $\%$ respectively). Thus, the numerical-experimental comparison can be considered to be in good agreement especially, if using Grease LB4.

\section{REFERENCES}

[1] Kalpakjian, S., Shmid, S.R. (2009). Manufacturing Engineering and Technology. Prentice Hall, Upper Saddle River.

[2] Joun, M.S., Moon, H.G., Choi, I.S., Lee M.C., Jun B.Y. (2009). Effects of friction laws on metal forming processes. Tribology International, vol. 42, no. 2, p. 311-319, D0l:10.1016/j. triboint.2008.06.012.

[3] MSC.Marc (2005). User Information, A, MSC Software Corporation, Newport Beach.

[4] Davis. J.R. (2004). Tensile Testing. ASM International, Ohio.

[5] Sofuoglu, H., Rasty, J. (2000). On the measurement of friction coefficient utilizing the ring compression test. Tribology International, vol. 32, no. 4, p. 327-335, D0l:10.1016/S0301679X(99)00055-9.

[6] Sutcliffea, M.P.F., Combarieu, R., Montmitonnet, P. (2004). Effect of additives on friction during plane strain compression of aluminium strip. Wear, vol. 257, no. 9-10, p. 1071-1080, D0l:10.1016/j.wear.2004.07.001.

[7] Yoon, E., Kong, H., Kwon, O., Oh, J. (1997). Evaluation of frictional characteristics for a pin-on-disk apparatus with different dynamic parameters. Wear, vol. 203-204, p. 341349, D0I:10.1016/S0043-1648(96)07365-6.

[8] Cho, H., Altan, T. (2005). Determination of flow stress and interface friction at elevated temperatures by inverse analysis technique. Journal of Material Processing Technology, vol. 170, no. 1-2, p. 64-70, D0I:10.1016/j.jmatprotec.2005.04.091.

[9] Lam, Y.C., Khoddam, S., Thomson, P.F. (1998). Inverse computational method for constitutive parameters obtained from torsion, plane strain and axisymmetric compression test. Journal of Material Processing Technology, vol. 83, no. 1-3, p. 62-71, DOI:10.1016/S0924-0136(98)00029-6.

[10] Giuliano, G. (2013). AA5083 Aluminium alloy constants identification through inverse analysis of the Erichsen test. Applied Mechanics and Materials, vols. 271-272, p. 208-211, DOI:10.4028/www.scientific.net/AMM.271-272.208.

[11] Giuliano, G. (2012). Influence of the metal sheet parameters on the results of the Erichsen test. Applied Mechanics and Materials, vols. 217-219, p. 2444-2447, D0l:10.4028/www. scientific.net/AMM.217-219.2444.

[12] Giuliano, G., Samani, F. (2013). Effect of lubrication on the Erichsen test. Applied Mechanics and Materials, vols. 365366, p. 425-428, D0I:10.4028/www.scientific.net/AMM.365366.425.

[13] Giuliano, G. (2013). Evaluation of the Coulomb friction coefficient by the Erichsen test. Applied Mechanics and Materials, vols. 365-366, p. 1190-1193, D0l:10.4028/www. scientific.net/AMM.365-366.1190.

[14] ISO 20482 (2003). Erichsen cupping test, International Organization for Standardization, Geneva.

[15] MSC.Marc, (2005). Element Library, B. MSC Software Corporation, Newport Beach. 